\title{
Real time polymerase chain reaction: a new powerful tool for the diagnosis of neurobrucellosis
}

\author{
J D Colmenero, M I Queipo-Ortuño, J M Reguera, G Baeza, J A Salazar, P Morata
}

J Neurol Neurosurg Psychiatry 2005;76:1025-1027. doi: 10.1136/jnnp.2004.04941 1

\begin{abstract}
Background/methods: We compared the diagnostic yield of a real time polymerase chain reaction (PCR) assay in cerebrospinal fluid (CSF) samples with conventional microbiological techniques for the diagnosis of neurobrucellosis. Following amplification of a $223 \mathrm{bp}$ sequence specific for Brucella genus, melting curve analysis was performed to verify the specificity of the PCR products.

Results: All six patients with neurobrucellosis (three meningitis and three meningoencephalitis) had a positive real time PCR assay, whereas CSF cultures and Wright seroagglutination tests were positive in only two and four cases, respectively. Brucella specific amplicons were easily demonstrated by their characteristic melting temperature in all the real time PCR assays.

Conclusion: LightCycler based real time PCR assay in CSF samples is more rapid and sensitive than conventional microbiological tests. This technique could be useful for the rapid diagnosis of neurobrucellosis.
\end{abstract}

B rucellosis is a worldwide zoonosis. In many countries, especially around the Mediterranean basin, and in the Middle East, India, Mexico, and Central and South America, the disease remains endemic. ${ }^{1}$

Human brucellosis is a systemic infection with a wide clinical spectrum. From 20-40\% of patients with brucellosis present focal complications, which can affect any organ or system, ${ }^{23}$ including the central nervous system (CNS), where it shows great clinical polymorphism. Although the incidence of CNS involvement is not high ( $1-2 \%$ of all cases) it results in considerable morbidity and mortality. ${ }^{2-4}$ Neurobrucellosis is often difficult to diagnose because the titres of specific antibrucella antibodies in cerebrospinal fluid (CSF) are usually low and the yield of the cultures is poor, with rates of positivity of just $40-50 \%{ }^{5}$

Among molecular techniques, the polymerase chain reaction (PCR) has already proved to be a very useful tool for the diagnosis of many CNS infections and is now considered the gold standard in some. ${ }^{67}$ We describe a SYBR Green I LightCycler based real time PCR assay for the rapid diagnosis of neurobrucellosis and compare its diagnostic yield with conventional microbiological techniques.

\section{PATIENTS AND METHODS \\ Patients}

From January 1998 to December 2002, six patients with neurobrucellosis were diagnosed, treated, and followed at the Infectious Diseases Unit or Neurology Service of Carlos Haya University Hospital, Spain. The diagnosis of brucellosis was established according to one of the following criteria: first, isolation of Brucella spp in blood or any other body fluid or tissue sample, or, second, the presence of a compatible clinical picture together with the demonstration of specific antibodies at significant titres or seroconversion. Significant titres were considered to be a Wright's seroagglutination $\geqslant 1$ / 160 or a Coombs antibrucella test $\geqslant 1 / 320$. Neurobrucellosis was diagnosed in patients with neurological symptoms and signs not otherwise explainable and at least one of the following criteria: (a) isolation of Brucella from CSF; (b) demonstration of antibodies to Brucella, agglutinating or nonagglutinating, in CSF (at any titre) in the presence of one or more abnormalities of the CSF $(>10$ cells $/ \mu$, protein levels $>45 \mathrm{mg} / \mathrm{dl}$, or glucose levels $\leqslant 40 \mathrm{mg} / \mathrm{dl}$ or $40 \%$ of the concomitant blood glucose level).

\section{Specimen collection and processing}

Samples of CSF were cultured onto blood and chocolate agar media, MacConkey agar, and Brucella agar (Biomedics, San Sebastian de los Reyes, Madrid, Spain). In order to rule out the possibility of mycobacterial and fungal infection all samples were also cultured onto Lowestein and Saburaud medium. The plates were incubated in a $10 \% \mathrm{CO}_{2}$ atmosphere at $37^{\circ} \mathrm{C}$ for at least 7 days. If growth appeared, the suspected colonies were identified by colonial morphology, Gram staining, oxidase, catalase and urease tests, and positive agglutination with specific antiserum.

\section{DNA extraction}

CSF samples were maintained at $-20^{\circ} \mathrm{C}$ until processing. DNA was extracted, by boiling, from $200 \mu \mathrm{l}$ to $1 \mathrm{ml}$ of CSF placed in a $1.5 \mathrm{ml}$ microcentrifuge tube and centrifuged for $15 \mathrm{~min}$ at $15000 \mathrm{Xg}$. The supernatant was eliminated and the pellet resuspended in $200 \mu \mathrm{l}$ of sterile water and centrifuged for $10 \mathrm{~min}$ at $15000 \mathrm{Xg}$. The supernatant was again eliminated and the pellet resuspended in $40 \mu \mathrm{l}$ of sterile water and subjected to boiling in a water bath for $10 \mathrm{~min}$, cooled on ice and centrifuged for $10 \mathrm{~s}$ at $15000 \mathrm{X} \mathrm{g}$, before storing at $-20^{\circ} \mathrm{C}$ until use. A total of $2 \mu \mathrm{l}$ of the suspension was used for PCR.

\section{Real time PCR with SYBR Green I}

Primers were selected from the conserved region of the gene that encodes an immunogenic membrane protein of $31 \mathrm{kDa}$ of Brucella abortus specific to the Brucella genus. ${ }^{8}$ The pair of 21 nucleotide primers $\mathrm{B}_{4}\left(5^{\prime}\right.$ TGG CTC GGT TGC CAA TAT CAA $3^{\prime}$ ) and $\mathrm{B}_{5}$ (5' CGC GCT TGC CTT TCA GGT CTG 3') (Tib Molbiol, Berlin, Germany) were used in the amplification process. PCR amplifications were performed in capillary tubes with $20 \mu \mathrm{l}$ of final volume in a LightCycler instrument (Roche Diagnostic, Mannhein, Germany). Reaction mixtures contained $2 \mu \mathrm{l}$ of LightCycler FastStart DNA master mixture for SYBR Green I (Roche Diagnostic, Germany), $0.5 \mu \mathrm{M}$ each primer, $4 \mathrm{mM} \mathrm{MgCl}_{2}$, and $2 \mu \mathrm{l}$ of DNA template. All capillaries were sealed and then centrifuged at $500 \mathrm{Xg}$ for

Abbreviations: CNS, central nervous system; CSF, cerebrospinal fluid; $\mathrm{CT}$, computed tomography; MR, magnetic resonance; PCR, polymerase chain reaction 
$5 \mathrm{~s}$ before amplification in a LightCycler instrument. Following activation of polymerase $\left(95^{\circ} \mathrm{C}\right.$ for $\left.10 \mathrm{~min}\right), 45$ thermocycles were run with $10 \mathrm{~s}$ denaturation at $95^{\circ} \mathrm{C}, 10 \mathrm{~s}$ annealing at $60^{\circ} \mathrm{C}$, and $9 \mathrm{~s}$ extension at $72^{\circ} \mathrm{C}$. The temperature transition rate was $20^{\circ} \mathrm{C} / \mathrm{s}^{-1}$ for all steps. The doublestranded PCR product was measured during the $72{ }^{\circ} \mathrm{C}$ extension step by detection of fluorescence associated with the binding of SYBR green to the product.

For data analysis, baseline adjustment was carried out in "none" mode and fluorescence curve analyses were carried out in the "fit points" mode of the LightCycler software. Positive controls based on DNA from $B$ abortus B-19 were included in all the tests, as were negative controls containing all the elements of the reaction mixture except template DNA. To guarantee the reliability of the results all the samples were processed in duplicate. To prevent contamination, universal precautions were exercised and one-way flow of DNA extraction and amplification were used. To avoid potential subjectivity, the status of each patient for Brucella infection was unknown during the PCR assay.

The test was only considered positive if the signal from the amplified fragment was clearly visible in both samples. In order to study the specificity of the technique, all the samples from the patients with brucellosis were paired with an equal number of samples from controls with subacute meningitis of a different aetiology (three tuberculous meningitis and one neurosyphilis) and two patients with brucellosis with no clinical evidence of neurological dysfunction or CSF abnormalities.

\section{RESULTS}

Five of the patients were men and one a woman. Their mean age was $37.6 \pm 16.6$ years (range: $21-69$ years). Four patients had usual contact with sheep or goats, one habitually consumed unpasteurised dairy products, and the other had no known prior exposure to Brucella infection.

Three patients had meningoencephalitis and three had meningitis. The duration of the symptoms prior to diagnosis was $90 \pm 138$ days (range: $5-365$ days). Four patients (66.6\%) presented fever and only three $(50 \%)$ had clear signs of meningeal irritation. Other relevant clinical data are shown in Table 1 .

Examination of CSF showed findings compatible with meningitis in all cases (Table 2). Antibrucella antibodies could also be demonstrated in CSF in all cases. Wright seroagglutination was positive in four cases $(66.6 \%)$ and in the other two cases non-agglutinating antibodies were shown by Coombs antibrucella test. In fact, Coombs antibrucella titres were higher than those of the agglutination test (Table 2).
CSF IgG values were increased in all cases (range: 2.34$6.42 \mathrm{~g} / \mathrm{L}$ ), and CSF protein electrophoresis showed oligoclonal bands in the three cases in who it was carried out.

Five patients had brain magnetic resonance (MR) imaging studies and the remaining patient a cranial computed tomography (CT) scan. In cases 1,2 , and 6 , one or more hyperintense lesions on $\mathrm{T} 2$ weighted images were seen in periventricular white matter, the right cerebellum, and the right occipital hemisphere, respectively. In the remaining three cases, neuroimaging studies were normal.

Brucella was isolated from CSF in two cases, whereas real time PCR assay was positive in all six cases and in each case Brucella specific amplicons could be easily distinguished by their characteristic melting temperature.

\section{DISCUSSION}

The clinical spectrum of neurobrucellosis is very heterogeneous. Different clinical pictures have been described, including meningitis, meningoencephalitis, intracerebral haemorrhage, benign intracranial hypertension, optic neuritis, arachnoiditis, polyradiculoneuritis, myelitis, and various combinations of these. ${ }^{9}$ Accordingly, neurobrucellosis, like neurosyphilis, is easily confused with many other neurological, neurosurgical, or even psychiatric processes. ${ }^{4} 59$

As seen in this and other studies, although the meninges are almost always involved in patients with neurobrucellosis, ${ }^{45910}$ the clinical signs of meningeal irritation are often lacking or, if present, may well be discrete. Furthermore, the fact that CSF cultures are negative in over $50 \%$ of cases, that IgG oligoclonal bands are often present, ${ }^{5}{ }^{10}$ and that these patients are not always seen by specialists in infectious diseases, explains why neurobrucellosis is not always considered in the differential diagnosis.

Adequate antibiotic treatment usually results in a good prognosis for patients with neurobrucellosis. However, 20$30 \%$ of patients still present neurological sequelae, which are clearly related with the delay in diagnosis and initiation of correct antibiotic treatment. ${ }^{9}$

Our group has reported that PCR based methods provide better results than conventional microbiological techniques for the diagnosis of both primary infection and relapses of brucellosis. ${ }^{11}$ Real time PCR is a new automated amplification technique that quantitatively monitors PCR products as they accumulate during thermal cycling. LightCycler technology (Roche Diagnostic, Germany) combines rapid amplification and sequence-specific detection of amplicons in an automated and standardised format. ${ }^{12}$ Because this probe does not require post-amplification handling, much faster assays are possible.

This study showed real time PCR assay to be positive in all six cases of neurobrucellosis, whereas the sensitivity of

Table 1 Summary of clinical finding

\begin{tabular}{|c|c|c|c|c|c|c|}
\hline & Patient 1 & Patient 2 & Patient 3 & Patient 4 & Patient 5 & Patient 6 \\
\hline Duration of the symptoms & 5 days & 3 months & 12 months & 4 weeks & 5 weeks & 30 days \\
\hline Fever & + & + & - & + & + & - \\
\hline Vomiting & - & - & + & + & - & + \\
\hline Headache & - & + & + & + & + & + \\
\hline Stiff neck & - & - & - & + & + & + \\
\hline Obtundation & + & - & - & - & - & + \\
\hline Papilloedema & - & - & - & + & - & - \\
\hline Impaired vision & - & + & - & + & - & + \\
\hline Hemiparesis & - & - & - & - & - & - \\
\hline Deafness & - & - & + & - & - & - \\
\hline Seizures & + & - & - & - & - & - \\
\hline Ataxia & + & + & + & - & - & - \\
\hline
\end{tabular}


Table 2 Biological and microbiological finding in CSF samples of patients with neurobrucellosis

\begin{tabular}{|c|c|c|c|c|c|c|}
\hline & Patient 1 & Patient 2 & Patient 3 & Patient 4 & Patient 5 & Patient 6 \\
\hline Glucose $\mathrm{mmol} / \mathrm{L}$ & 4.49 & 2.55 & 1.05 & 0.61 & 1.66 & 1.27 \\
\hline CSF/plasma glucose ratio (\%) & 47 & 41 & 19 & 13 & 42 & 24 \\
\hline CSF WBC ml (\% lymphocytes) & $8(75 \%)$ & $85(90 \%)$ & $825(70 \%)$ & $579(75 \%)$ & $540(70 \%)$ & $45(95 \%)$ \\
\hline Protein $\mathrm{g} / \mathrm{L}$ & 0.85 & 3.03 & 5.35 & 0.84 & 0.80 & 1.80 \\
\hline Real time PCR & + & + & + & + & + & + \\
\hline Adenosine deaminase $\mathrm{U} / \mathrm{L}$ & ND & 11 & 35 & 17 & 7 & 14 \\
\hline Culture & - & B melitensis & - & - & B melitensis & - \\
\hline Agglutination* & 20 & 320 & - & - & 40 & 80 \\
\hline Coombs test ${ }^{*}$ & 160 & 5120 & 1280 & 640 & 160 & 5120 \\
\hline
\end{tabular}

*Expressed as reciprocal of titres.

CSF, cerebrospinal fluid; ND, not done; PCR, polymerase chain reaction; WBC, white blood count.

seroagglutination and cultures of CSF samples was $66.6 \%$ and $33.3 \%$, respectively. Real time PCR was negative in all the control samples, which is in keeping with the specificity of the primers used. Previous studies have demonstrated the high specificity of the B4 and B5 primers with a wide panel of microorganisms. ${ }^{13}$

The LightCycler assay used is rapid, easy, and objective, allowing sensitive and specific identification of PCR products in less than 2 hours. Moreover, the technique is a closed-tube system; this considerably reduces the risk of contamination by product carryover and allows simultaneous handling of a large number of samples, making it very suitable for use in a clinical laboratory. Finally, it should not be forgotten that Brucella spp are class III pathogens requiring special protection measures. PCR assays completely obviate the need for direct handling of the pathogen, thus greatly reducing the risk of infection of laboratory personnel.

In conclusion, although the results of this study are preliminary, the high sensitivity and specificity of this real time PCR assay, together with its speed and versatility, make it a very useful tool and could lead to it being considered the new gold standard for the diagnosis of neurobrucellosis.

\section{ACKNOWLEDGEMENTS}

This work received financial support from F.I.S. grant PI02/0957, Red Temática para la Investigación en Brucelosis, Instituto de Salud Carlos III (ISCIII) grant G03/204, and Andalusian Regional Government grant SAS 70/02. We thank Ian Johnstone for his help with the English language version of the text.

\section{Authors' affiliations}

J D Colmenero, J M Reguera, Infectious Diseases Unit, Department of Internal Medicine, Carlos Haya University Hospital, Málaga, Spain M I Queipo-Ortuño, G Baeza, P Morata, Department of Biochemistry and Molecular Biology, Faculty of Medicine, Málaga, Spain

J A Salazar, Neurology Department, Carlos Haya University Hospital, Málaga, Spain
Competing interests: none declared

Correspondence to: J D Colmenero, Unidad de Enfermedades Infecciosas, Hospital Universitario Carlos Haya, Avda Carlos Haya s/n, 29010 Malaga, Spain; jdcolmenero@telefonica.net

Received 8 July 2004

Revised version received 30 September 2004

Accepted 7 October 2004

\section{REFERENCES}

1 Trujillo IZ, Zavala AN, Caceres JG, et al. Brucellosis. Infect Dis Clin North Am 1994;8:225-41.

2 Young EJ. An overview of human brucellosis. Clin Infect Dis 1995;21:283-90.

3 Colmenero JD, Reguera JM, Martos F, et al. Complications associated with Brucella melitensis infection: A study of 530 cases. Medicine (Baltimore) 1996;75:195-211.

4 Bouza E, García de la Torre M, Parras F, et al. Brucellar meningitis. Rev Infect Dis 1987;9:810-22.

5 Al-Deeb SM, Yaqub BA, Sharif HS, et al. Neurobrucellosis: Clinical characteristics, diagnosis and outcome. Neurology 1989;39:498-501.

6 Tang YW, Mitchell PS, Espy MJ, et al. Molecular diagnosis of herpes simplex virus infections in the central nervous system. J Clin Microbiol 1999:37:2127-36.

7 Joseph P, Calderon JP, Gilman MM, et al. Optimization and evaluation of a PCR assay for detecting toxoplasmic encephalitis in patients with AIDS.J Clin Microbiol 2002;40:4499-503.

8 Baily GG, Krahn JB, Drasar BS, et al. Detection of Brucella melitensis and Brucella abortus by DNA amplification. J Trop Med Hyg 1992;95:271-5.

9 Mclean DR, Russell N, Khan MY. Neurobrucellosis: Clinical and therapeutic features. Cin Infect Dis 1992;15:582-90.

10 Pascual J, Combarros O, Polo JM, et al. Localized CNS brucellosis: report of 7 cases. Acta Neurol Scand 1988;78:282-9.

11 Morata P, Queipo-Ortuno MI, Reguera JM, et al. Development and evaluation of a PCR-enzyme-linked immunosorbent assay for diagnosis of human brucellosis. J Clin Microbiol 2003;41:144-8.

12 Harder TC, Hufnagel M, Zahn K, et al. New LightCycler PCR for rapid and sensitive quantification of parvovirus B19 DNA guides therapeutic decision-making in relapsing infections. J Clin Microbiol 2001;39:4413-9.

13 Casañas MC, Queipo-Ortuño MI, Rodriguez-Torres A, et al. Specificity of a polymerase chain reaction assay of a target sequence on the 31-Kilodalton Brucella antigen DNA used to diagnose human brucellosis. Eur $J$ Clin Microbiol Infect Dis 2001;20:127-31. 